where training in the medical schools was not recognised. It was disturbing to learn, however, that there was evidence of disadvantage for British doctors who happened to have a dark skin when it came to career progression in medicine. We looked at a number of ways in which these problems could be solved. These could include shortlisting procedures where no names were provided, advice for doctors from ethnic minorities, and a broader approach to interviewing for senior posts. It was recognised that the role of the College representative was extremely important on appointments committees as he or she was outside the local hierarchy.

In conclusion, it was thought that the day had been extremely valuable. Training in various aspects of ethnic issues should be much more widely available in senior registrar training in child psychiatry, and also in continuing education at consultant level.

The small, free-standing nature of the meeting in which colleagues spent the day together, including an excellent lunch, encouraged openness of discussion around difficult issues.

\title{
A vision of community mental health services*
}

\author{
Paul Dedman, Senior Registrar, City General Hospital, Stoke-On-Trent ST4 6QG
}

This one-day conference was organised by The Royal College of Psychiatrists in collaboration with The Centre for Mental Health Services Development, and featured two seminal advocates of acute home psychiatric treatments, Professor Leonard Stein and Dr John Hoult. Speakers were more concerned with realities than visions, but to hear how others set about their work in this innovative field may perhaps inspire visions of one's own.

Professor Stein spoke about the 'disaster' of deinstitutionalisation in the US with frequent readmission and episode-orientated care. He then contrasted that with the service with which he has been involved for over 15 years in Madison, Wisconsin, which has been oriented towards continuing care in the community for the seriously mentally ill to provide a seamless service outside the mental hospital. This service includes crisis resolution services for acute illness, mobile community treatment teams for the long-term mentally ill, out-patient clinics and rehabilitation facilties. Principles employed include an assertive approach to limit drop-out rate, 24 hour availability, a 'gatekeeper' role of community services in relation to hospital admission, domiciliary visits if necessary and the use of respite houses or even hotel rooms! The resulting decrease in hospital bed usage has led to a situation where $85 \%$ of resources are now being channelled into community services.

Dr Hoult spoke about his work in Sydney where the Madison approach has been used extensively as part of a routine service. These services have been evaluated (thus countering the criticism that it is only

*Conference held at The Royal College of General Practitioners, London SW7. high-morale experimental teams which are studied) and appear to be superior to in-patient care in terms of cost, clinical outcome and patient satisfaction. He spoke of the importance of defining the patient group in the planning of any service right from the outset.

Two speakers from this country described their approaches to the setting up of integrated community-based services. Dr Tom Burns' description of the Dingleton approach in Wimbledon, a service built out of existing resources, which had more modest success in terms of clinical outcome but which exerted a positive effect on inter-disciplinary teamwork and the variety of treatment types offered. Dr Jan Scott from Newcastle described the first three years of a service where the average bed usage for a population of 56,000 was just four.

Further international perspectives were provided by Dr Jan Pfeiffer who described the establishment of community services in Prague and Dr Pino Pini from Florence who spoke about the comprehensive network of services that have grown up in the wake of the Law 180 reform which virtually abolished institutional care at a stroke.

The discussion groups, facilitated by the speakers, were particularly illuminating and revealed a certain groundswell of scepticism that overseas models were appropriate to the UK with its existing infrastructure of day hospitals and GPs. Concern was expressed over whether radical community approaches could be seen as 'anti-hospital' although all speakers did acknowledge the need for hospitalisation in some cases. Other issues included whether home treatment was suitable for deprived inner-city areas and the influence of the purchaser-provider model on community approaches. 